\title{
Indivíduo, subjetivação e cultura ${ }^{1}$
}

\author{
Hubert Vincent* \\ http://dx.doi.org/10.1590/0103-7307201507607
}

\section{Resumo}

É sempre num sentido substancialista que compreendemos a noção de diferença: diferenças existiriam, seriam dadas, e nossa responsabilidade estaria em nos adaptarmos a elas. Quer se valorizem, quer se critiquem nossas sociedades pós-modernas, elas parecem situar no cerne de suas atenções a preocupação com as diferenças individuais. 0 objetivo deste artigo é conside-

* Universidades das Ciências da Educação da Universidade de Rouen, Mont-Saint-Aignan Cedex, França. hubert.vincent@ univ-rouen.fr rar essa valorização e essa crítica, sem privilegiar uma ou outra. Tomando apoio em Montaigne, procura mostrar que o indivíduo não é assimilável a uma realidade substancial e estável, e que, se quisermos refletir sobre o que seria, na educação, a preocupação com a individualidade, é outra a direção que deveremos tomar. 0 que seria, assim, uma "educação principesca”, a admitirmos que esse tema clássico da filosofia da educação seja o tema em que a filosofia reflete essa preocupação com o indivíduo, com Montaigne particularmente, mas também com Emerson, Nietzsche, Dewey e, mesmo, Kant? Em que medida, além disso, a educação do indivíduo assim compreendida se articula com a preocupação com a cultura e as suas obras, a ponto de permitir nossas condições de subjetivação?

Palavras-chave: educação, pós-moderno, diferença, cultura e obras, autoconfiança

1. "Individu, subjectivation et culture", traduzido por Dorothée de Bruchard. 


\title{
Individual subjectification and culture
}

\begin{abstract}
It's always in a substantialist way, that we understand the notion of difference: there would be differences, they would be given, and our responsibility is to adapt to them. Whether we like it or dislike our postmodern societies, they seem to put at the heart of their projects this concern for individual differences.

The purpose of this article is to contest both the valuation that this criticism. Building on Montaigne, it endeavors to show that the individual is in no way comparable to a substantial and stable reality and if we want to think about what may be the concern of individuality in the éducation, we must take an other direction. What is a "princely education" if we admit that this classic theme of philosophy of education is the theme in which philosophy reflects this concern for the individual, especially in Montainge, but also Emerson, Nietzsche, Dewey, and even Kant? To what extent then, the education of the individual, such understood, can be articulated with culture and his works, to allow us our conditions of subjectivation?
\end{abstract}

Keywords: Paulo Freire, school education, democracy 
Qualquer que seja a diversidade de perspectivas descortinada pela preocupação com as diferenças, importa saber de que maneira a didática pode, finalmente, levar em conta as diferenças individuais, deixando de acreditar que os mesmos modos de ensino convenham para todos, que os mesmos objetos interessem a todo mundo e que seja essencial fazer com que todos partilhem os mesmos objetivos. "Finalmente", pois se admite, atualmente, que "a pedagogia tradicional" desconheceu por muito tempo tanto as diferenças individuais quanto a diversidade de interesses que nos envolvem e sobre a qual ela agora deveria se calcar. De modo que já não se discute o direito a essa tendência, mas, simplesmente, seus modos de realização.

Seria preciso, além disso, que a didática se abrisse para as nossas diferenças sociais e para a variedade de nossos estilos psicológicos. Ela teria, assim, de levar em conta as diversas expectativas e os poderes diversos dos alunos, conforme a origem dos meios sociais, ao invés de pretender que uma mesma pedagogia convenha para todos, quando, na verdade, serve apenas para alguns, já preparados por seu meio social. Ela também deveria levar em conta os superdotados e os subdotados, e adaptar seus ritmos a essas diferenças; precisaria ser receptiva, além disso, a todas as formas de deficiência. É o que todos parecem estar exigindo, particularmente as famílias.

Assim, as diferenças seriam ponto pacífico, e a tarefa da didática consistiria em conhecê-las o suficiente para agir, com cada um, de maneira adequada. Deve e deveria haver uma pesquisa, um conhecimento capaz de nos dizer o que convém ao perfil de cada um. Cada um de nós é portador de uma diferença, é portador de uma norma própria, e trata-se, para a didática como para a pedagogia, de levá-las em conta.

1. Pode-se dizer que, em certo sentido, essa exigência não é nova. Fazia-se ouvir já desde a Renascença, momento em que se assentou a subjetividade moderna. Montaigne (1992) é, decerto, uma das fontes desse movimento, quando escreve:

Aqueles que, como reza nosso costume, se dispõem, com uma mesma lição e igual maneira de conduzir, a instruir vários espíritos bem distintos no grau e na forma, não será de estranhar que, numa multidão de crianças, só encontrem duas ou trêsnas quais frutifique seu ensinamento (p. 115). ${ }^{2}$

O fato, porém, é que esta tendência é vista hoje em dia como uma tendência de nossas sociedades

2. "Ceux qui, comme porte notre usage, entreprennent, d'une même leçon et pareille mesure de conduire, régenter plusieurs esprits de si diverses mesures et formes, ce n'est pas merveille si, en tout un peuple d'enfants, ils en rencontrent à peine deux ou trois qui rapportent quelque juste fruit de leur discipline." 
pós-modernas. Ou assim é descrita, pelo menos, por diferentes autores que trataram de analisá-la. Dentre esses, detenho-me nas análises de S. Johsua, que passo a expor brevemente no intuito de depreender, a partir daí, algumas coordenadas do problema referente à avaliação dessa tendência.

1.1. Pós-moderna é, segundo ele, uma sociedade ou época em que já se tornou impossível dizer: "Uma vez que a escola é falsamente igual para todos, melhor então que seja claramente 'diversa', 'diferente', já que não queremos dizer desigual” (Johsua, 1999, p. 75). A atenção às diferenças nasce do reconhecimento de que o projeto igualitário, do qual a escola é um importante veículo, deve ser abandonado. Se ela própria não logra construir um pouco de igualdade; se faz, inclusive, o contrário, então deve ser abandonado o projeto de igualdade (Lyotard [1979] diria o grande relato), e só nos restar deixar agirem as diferenças e oferecer um serviço educacional de que cada qual, segundo seus próprios recursos, necessidades e desejo, possa se apropriar a seu bel-prazer. 0 autor destaca, evidentemente, a proximidade dessa perspectiva com as políticas ultraliberais. Por trás dessa perspectiva se delineia, com efeito, o desengajamento do Estado em relação ao sistema educacional e a privatização deste último. 0 desejo de uma educação calcada nas diferenças estaria, dessa forma, fazendo o jogo de determinadas tendências do neoliberalismo. Temos aí, portanto, uma primeira coordenada do problema.

1.2. Pós-moderna seria, além disso, uma sociedade para a qual a "forma tradicional da escola” é necessariamente hostil a qualquer autêntica subjetivação: "Estamos aqui em pleno fascínio pós-moderno pela suposta fragmentação dos indivíduos. Se a racionalidade está de um lado (sempre enganosa), a subjetividade está de outro (sempre autêntica)." (Johsua, 1999, p. 69). Assim, portanto, o apreço pelas diferenças estaria hoje ligado a uma preocupação com a autenticidade que, por si só, se oporia frontalmente a todo elemento de racionalidade, a todo elemento institucional e, a fortiori, à escola. Embora Johsua (1999, p. 69) a ancore na experiência da adolescência, essa oposição remete, a seu ver, a uma característica de nossa época.

Mais uma vez, contudo, podemos aqui detectar em Montaigne (1992, p. 116) este sentido da diferença: "Quem segue o outro, não segue nada. Não encontra nada,

3. "Qui suit un autre, il ne suit rien. Il ne trouve rien, voire il ne cherche rien." aliás, não busca nada”, 3 e cita Sêneca para sustentar sua afirmação: “Não vivemos sob um rei; cada 
qual que disponha de si mesmo". Essa tentação de centrar a educação no indivíduo não é exclusiva, portanto, de nossas sociedades pós-modernas, é anterior a elas. De modo que deveríamos, no mínimo, atentar para o uso dessa categoria "pós-moderno", que parece ser muito mais polêmica do que propriamente científica4.

Seja como for, esse aspecto redunda, porém, na segunda coordenada do problema: o culto da diferença é valorização da autenticidade e crítica a todo elemento de racionalidade, a toda instituição ou pretensão do bem comum5.

1.3. O último aspecto que eu gostaria de extrair dessas análises concerne à relação com o saber e à relação com a norma escolar. 0 que o autor reprova nessa tendência, própria de nossa época, de dar forte ênfase à escola como lugar de socialização, em detrimento da transmissão do saber, é justamente o fato de essa insistência nas questões da socialização nos levar a ignorar tudo que está em jogo na transmissão do saber. E essa transmissão não passa de uma modalidade de reprodução das desigualdades. Assim escreve ele, visando retomar e explicitar o discurso que hoje nos domina:

A Escola não pode em absoluto ser descrita, mesmo parcialmente, como transmissora de sistemas de saberes e técnicas. Mesmo que estes se manifestem, seria vão querer atribuir-lhes, a não ser marginal, e sempre secundariamente, uma pertinência passível de ser demonstrada para além do espaço escolar .... Quer se julgue positivamente, conforme tradição da sociologia americana, essa função de inculcar normas e posições sociais, quer dela se desconfie de forma crítica, esse efeito "socialização", embora incontestável, não deixa de suscitar uma pergunta: trata-se da socialização (no singular), ou de uma socialização entre outras? No caso de "uma" socialização, o que é que a especifica? E, mais que nada, porque a inculcação deste sistema de normalização requer particularmente a existência da Escola (Joshua, 1999, p. 65-66).

A terceira coordenada do problema que eu gostaria de destacar aqui pode então ser analisada assim: qual é exatamente a relação entre, de um lado, o saber e sua transmissão e, de outro, a preocupação com socialização e normalização? Se decerto é um erro, como mostra Johsua (1999,

4. Disso nos convencemos facilmente, se reparamos que, para autores tão autorizados quanto Johsua, a saber, os sociólogos Boltansky e Chiapello (1999, p. 549 e seguintes, principalmente), o pós-moderno é tido como uma crítica radical do valor de autenticidade. Pelo menos, é o que ambos julgam poder depreender de certas temáticas deleuzianas e derridianas.

5. G. Deleuze, em Différence et répétition (1968), já frisava que a atenção que dava à diferença não significava, de modo algum, valorizar as diferenças em si. Vide, notadamente, a introdução, página 2, assim como as páginas 253 e seguintes. Ele retomaria esta primeira crítica naquela que faria, posteriormente, das minorias que se reterritorializam. 
p. 67), subordinar totalmente a lógica da transmissão do saber à lógica da socialização como imposição de normas, se esta subordinação se atém a um formalismo incapaz de examinar com precisão os modos de fazer e transmitir, o fato é que essas duas lógicas certamente não são de todo independentes; e a questão seria então se, e como, o saber consegue fazer a diferença e tornar possível uma relação, consigo e com os outros, que difira da reprodução das posições e normas sociais. Qual seria a escapatória, e em que condições? Como pode o saber construir sua própria legitimidade ou, pelo menos, uma de suas legitimidades, afora essa escapatória que ele autoriza?

Esses elementos, mais uma vez, não são originais, e não é como tais que Johsua os apresenta; pretendem explicitar algumas teses ou contextos mentais que seriam mais ou menos os nossos, ilustrativos de nossa época e das limitações que the são próprias. Se são assim lembrados, contudo, é para serem criticados, e com o intuito, para Johsua pelo menos, de recentrar a reflexão na preocupação com o estudo das obras como base essencial de uma cultura comum. Esses mesmos elementos e a mesma crítica desses elementos se encontrariam, assim, em outros autores. ${ }^{6}$ Nesse sentido, eu diria que eles formulam nossa doxa, ou dispõem as coordenadas com que deveríamos equacionar a questão das diferenças e sua tomada em consideração.

Parece-me, contudo, que esses problemas não são novos, nem são meros sinais de um desacerto de nossa época. 0 que é, afinal, essa preocupação com o indivíduo e como compreendê-la? Se as reflexões sobre a educação podem dificilmente ignorar essa referência à individualidade e à sua própria diferença, a questão é: como devemos pensá-la? Será ela, notadamente, redutível à menção de uma subjetividade autêntica e ciosa de sua autenticidade? Será redutível a essa desconfiança ou, mesmo, rejeição de toda institucionalização comum a todos? Só teríamos a objetar-lhe, enfim, a necessidade de formas comuns?

O que é, afinal, o indivíduo; como compreender essa referência à individualidade e à sua própria diferença em nossas reflexões sobre a educação? Será possível, e com que condições referentes à cultura, repensar a oposição entre o indivíduo e a transmissão da cultura? Não será possível pensar simultaneamente a preocupação com a individualidade, com sua forma própria, e a atenção às obras como espaço de uma

6. Na França, especificamente, no artigo de Denis Kambouchner (1995) sobre a noção de cultura. mesma cultura comum? Serão ambos tão opostos como se diz, e será impossível mostrar que essa 
oposição é, na verdade, enganosa? E, sem dúvida, com a condição de outra definição do que devemos entender por indivíduo e do que devemos entender por cultura comum? É o que vou tentar fazer, tomando apoio em Montaigne.

\section{A forma individual das reflexões sobre a educação}

Embora de fato encontremos em Montaigne uma valorização do indivíduo e do seu juízo próprio, os traços dessa individualidade nos apontam um aspecto bem distinto da diferença.

Vou destacar pelo menos dois desses traços.

2.1. O primeiro diz respeito a uma certa ideia da natureza infantil. Montaigne começa dizendo que, se pôr crianças no mundo é fácil, bem mais difícil é educá-las: “Não há muito engenho em plantá-las; mas, depois que nascem, cabe-nos outro cuidado, de pleno atarefamento e receio, para formá-las e nutri-las".7 Destaco desde já que os sentimentos e as posturas que acompanham o nascimento das crianças são, de um lado, o receio; e, de outro, isso que Montaigne (1992, p. 114) chama de "atarefamento". Na língua francesa, esse termo conota um determinado tipo de trabalho, ou determinada atitude em relação ao trabalho: uma "tarefa" é um trabalho cansativo e ingrato, pouco gratificante. Montaigne fala em "atarefamento" como se pais e educadores se empenhassem demais e sempre fizessem um pouco demais, sem que esse “demais" fosse garantia de um “melhor”. É este o problema da educação: nunca temos realmente certeza do resultado.

A que se devem esse dois sentimentos?

A mostra [manifestação] de suas inclinações é tão frágil nessa tenra idade, e são tão obscuras, incertas e falsas as promessas, que é difícil formar um juízo sólido.... 0s filhotes dos ursos, dos cães, mostram sua inclinação natural; mas os homens, entregando-se incontinenti a hábitos, opiniões, leis, facilmente se modi-

ficam ou se disfarçam. ${ }^{\mathbf{8}}$ (Montaigne, 1992, p. 114).

Tais palavras podem parecer bem simples; dizem, porém, coisas muito importantes e, principalmente, contrárias aos nossos modos usuais ou científicos de pensar a indefinição infantil.

7. “llyapeud'industrieàlesplanter; mais, depuisqu'ilssont nés, on se charge d'un soin divers, plein d'embesognement et de crainte, à les dresser et nourrir."

8. "La montre de leurs inclinations est si tendre en ce bas âge, et si obscure, les promesses si incertaines et fausses, qu'il est malaisé d'y établir aucun solide jugement (...) Les petits des ours, des chiens, montrent leur inclination naturelle; mais les hommes, se jetant incontinent en des accoutumances, en des opinions, en des lois, se changent ou se déguisent facilement." 
Dizem, antes de mais nada, que os pais estão diante de uma certa indefinição e que o problema, para eles, está menos em reduzi-la do que em enfrentá-la. A norma, aqui, está mesmo na capacidade de sustentar essa indefinição, não em instituir um fim. A diferença não “é”; portanto, não é dada, e, assim, não faz sentido querer se adaptar a ela. Pode aqui parecer que Montaigne se antecipa às teses mais tardias de Fichte ou de Kant, afirmando que o homem, à diferença dos animais, não possui natureza, que é esse vazio, ou esse nada, que dá liberdade à sua ação e à sua obra, quer como indivíduo, quer como humanidade. Que existe, portanto, esse vazio que autoriza, então, todo projeto educativo e a educação, em si, como projeto de estabelecimento ou instituição. Julgamos, então, reencontrar a possibilidade de fixar objetivos, de instituir. Montaigne, no entanto, não diz nada disso.

Uma vez que - e é este o segundo ponto - isso com que os pais ou adultos se deparam não é um nada; são, diz Montaigne, “inclinações”, inclinações que são não apenas plurais, são também obscuras; são, mais que isso, incertas e gostam, por fim, de se esconder e disfarçar. De modo que estamos, segundo Montaigne, diante de uma pluralidade movente. 0 que existe é o jogo de algumas inclinações. Umas aparecem, como que timidamente, sem saber bem o que há de ser delas. Outras se mascaram, se escondem, decerto para prosperar mais à vontade longe do olhar social. Algumas só aparecem para desaparecer em seguida e, porque tiveram lugar, cedem espaço para outras. Em suma, como se diz, a criança se busca, e se buscar é se experimentar, “se ensaiar", mas é também se furtar, se esconder, para se proteger.

Não há, simplesmente, inclinações profundas e inclinações superficiais. Mas o que há, também, é uma lógica da máscara e do disfarce: a infância ora se mostra, ora se esconde, e gosta desse jogo. Ela é como que a guardiã dele ou do seu self.

Assim, esse jogo como um todo é que deve ser respeitado, e não esta ou aquela inclinação que o indivíduo teria.

Somos remetidos a uma pluralidade movente ou metaestável, que é também o jogo de nossa soberania. Temos aí um conceito de diferença absolutamente específico. Não há nenhum dado claro e evidente; não há nenhum conhecimento da criança e de sua natureza própria. O que há é um sistema metaestável de inclinações e interesses. A consequência imediata que podemos tirar deste texto é dupla: por um lado, é impossível a educação se fundamentar numa "natureza” que ela deveria respeitar. Mas ela também deve, por outro, ser capaz de acompanhar essa individualidade metaestável e autorizar seus jogos próprios, seus próprios ensaios e tentativas, assim 
como seu jogo de se mostrar e/ou esconder livremente. Como?

A resposta que surge de imediato em Montaigne (1992, p. 114-115) e seria objeto de suas elaborações posteriores, é a seguinte: “Quanto a esta dificuldade, contudo, minha opinião é de sempre orientá-las para as coisas melhores e mais proveitosas, e de que pouco nos devemos ater a essas levianas adivinhações e prognósticos que deduzimos dos impulsos de sua infância”. ${ }^{9}$

São, portanto, aqui, as noções de "proveitoso" e "melhores coisas" que oferecem a solução. Qual o sentido dessas noções? O que significa “melhores coisas”? Estará Montaigne se referindo à noção de uma forma comum, de uma cultura ou de um saber comum, visto e compreendido como esse mínimo comum entre nós, e que se deveria instituir em todo mundo, cada qual sendo livre em seguida para pôr em prática sua própria diferença? Ou estará se referindo, ao invés, a uma espécie de promessa? 0 proveitoso, o melhor, com efeito, só se revelou como tal porque foi melhor para alguns indivíduos, porque muitos souberam dele se apropriar e com ele fazer alguma coisa, de modo que o esperado é que possa sê-lo novamente e que outros indivíduos possam, a seu modo, dele fazer uso? Neste segundo caso, não se trata simplesmente da instituição, nos alunos, de um saber comum; trata-se, antes, de um poder de retomada desses elementos de cultura de que outros, anterior e regularmente, souberam tirar partido ou proveito; trata-se da repetição, singular, de algo já antes retomado muitas e muitas vezes, demonstrando assim sua capacidade de ser retomado de forma diferente. Trata-se, portanto, da retomada em si, do fato da retomada. Não uma forma comum de possibilidade, e, sim, a preocupação de atestar a virtualidade de certos bens.

2.20 segundo aspecto que eu gostaria de destacar concerne à forma específica de uma educação do indivíduo. Montaigne é bastante claro neste ponto: quem se vai educar é um príncipe. Não só seu ensaio é dirigido a uma princesa e lhe fala de seu filho, mas a norma educativa é uma norma principesca: "vosso filho é um príncipe, vossos filhos são príncipes”. O que é uma educação principesca?

2.2.1 Segundo ele, um príncipe, para começar, será necessariamente um menino: “Esse homenzinho que ameaça sair lindamente de vós (sois por demais generosa para não iniciardes com um
9. "Toutefois, en cette difficulté, mon opinion est de les acheminer toujours aux meilleures choses et plus profitables, et qu'on se doit peu appliquer à ces légères divinations et pronostics que nous prenons des mouvements de leur enfance." 
varão)" $\cdot{ }^{10}$ É certo que se evidencia aqui uma relativa preferência por meninos (relativa, já que se trata apenas do primeiro filho). Mas o que se vê igualmente é que a individualidade assume a forma de um movimento específico: uma saída, uma linda saída, um certo alento, ausência de hesitação ou recuo; ou ainda, como dirá Montaigne, um certo “livre andar”.

Essa característica se encontra ao longo de todo o ensaio, e pode ser expressa da seguinte maneira: existe uma espontaneidade na natureza infantil, e nossa responsabilidade primeira é respeitá-la, e não sufocá-la a pretexto de orientá-la ("tanto nos submeteram às andadeiras que perdemos nosso livre andar") ${ }^{11}$. Ela é que é o nosso suporte, e, se a criança perde esse gosto de se mostrar, de se expor, de avançar livremente; se perde, portanto, esse “livre andar" que a define como tal, então estará ausente a condição da educação.

Do ponto de vista do espírito, esse "livre andar" será o juízo como poder de escoIha e discernimento das coisas por si próprio. Para o preceptor, o desafio imediato é "testar a alma da criança, levando-a a experimentar e escolher por si própria". ${ }^{12} \mathrm{~A}$ alma principesca detém, portanto, um certo poder de experimentar, discernir, que é preciso “expor” para bem poder vê-la, para dá-la a ver e para que assim ela se forme. Assim procedem também, julga Montaigne, os professores de ginástica: primeiro pedem a seus alunos que façam cambalhotas, para então, e só então, corrigir, ajustar, acertar.

Montaigne, é claro, não irá parar por aí: dirá como esse juízo vai se educando aos poucos por seu próprio movimento, de como se educa pelo confronto com os livros, com os diferentes costumes, com os outros em justas oratórias e também pela escuta e apropriação do que é oferecido ao aluno por seu preceptor e auxiliares. Dirá também como esse "livre andar" não exclui a inabilidade, nem, sobretudo, a reserva e a expectativa, e nem mesmo a modéstia. Como tampouco exclui uma educação para a dúvida, pois, justamente, é próprio das almas fortes poder duvidar de suas crenças, ou considerá-las firmes o bastante para poderem ser contestadas, reais o bastante para poderem ser contestadas e transformadas. Dirá, por exemplo, num trecho muito importante sobre a educação para o diálogo, que não é em

10. "Ce petit homme qui menace de faire une belle sortie de chez vous (vous êtes trop généreuse pour commencer autrement que par un mâle."

11. "On nous a tant assujettis aux cordes que nous n'avons plus de franche allure."

12. "...mettre l'âme de l'enfant sur la montre, lui faisant goûter et choisir d'elle-même”. qualquer lugar, com qualquer pessoa, que posso arriscar minhas opiniões e meu pensamento; da mesma forma que todo jogador bem sabe que mais vale, para uma boa partida, ter adversários nem muito fracos nem muito fortes. Assim, a edu- 
cação para o livre andar não se dá sem uma educação para a cautela circunspecta, a reserva e a expectativa, para a escolha dos parceiros ou dos objetos com os quais haja algum tipo de envolvimento - sem, enfim, uma cultura da dúvida. Ainda assim, o que qualifica a educação como principesca é esse pressuposto do livre andar, o pressuposto de que nossos movimentos espontâneos estão certos, não são originalmente errados ou marcados pelo fracasso e, em outras palavras, não precisam ser endireitados. A criança príncipe é uma criança não tímida, não temerosa, nada ansiosa em seus movimentos e ensaios, mas, pelo contrário, pronta para corrigi-los e realizá-los mais claramente e melhor. O desafio está em conseguir resgatar essa criança ou esse movimento.

Creio que todo professor tem logo cedo a experiência de que é difícil, em situação escolar, resgatar esse livre andar naqueles que ensina. Não é fácil, longe disto, redescobrir o próprio poder de fazer ou pensar, quando se diversificam diante de nós as situações de aprendizagem; quando, por exemplo, nos pedem para saltar em altura ou arremessar três quilos a distância, ou bem declamar um poema, ou desenvolver uma ideia de Kant. Quando se lida com uma classe inteira, que olha para nós e nos espera. Difícil, mas decerto não impossível, me parece, como demonstra um mínimo olhar ao trabalho de alunos que tiveram a oportunidade de fazer algo por si próprios, sem pensar o tempo todo que seriam avaliados e "tinham que fazer direito”. Não é fácil redescobrir, voltar a ser capaz de iniciativa diante de, e com, materiais culturais. Mas não é inalcançável. E é também esta a condição da educação: “experimente, depois a gente vê". Assim também o professor faz a experiência de que é mesmo na redescoberta dessa iniciativa que a criança ou aluno começa a julgar o material que lhe é proposto, nele fazer escolhas e se encontrar; e que a educação pode então, de fato, começar. E decerto não se trata de conseguir resgatar tudo, e logo: faz parte do processo educativo saber que esse resgate às vezes requer tempo, requer ruminação, perseverança, e, aí é que está, os alunos muitas vezes não dispõem de tempo para isso. Também faz parte do processo educativo esperar que, para além de, e graças a, longas hesitações, longas timidezes, algum movimento próprio nasça e se ponha ao trabalho.

O que torna a educação impossível é o retraimento e a timidez, não por parte dos alunos, é claro, mas da relação educativa em si e, evidentemente, do social. Aqui, nenhuma naturalidade, nenhuma evidência, e a timidez é justamente aquilo de que é preciso livrar-se. Nisso reside, me parece, uma educação principesca, e não é nada 
certo que, no âmbito das famílias, a divisão entre as que educam príncipes e aquelas mais zelosas de conformidade coincida com as distinções sociais ${ }^{13}$.

\subsubsection{Sem dispor de tempo para me estender como deveria sobre toda a tradição} que começa aqui ${ }^{14}$, gostaria ao menos de mencionar uma referência importante, a saber, Dewey, embora seja conhecido e renomado por sua ênfase no coletivo e na comunidade.

Vou me apoiar num trecho de Démocratie et Éducation, em que Dewey, depois de analisar o método geral de aprendizado (que equivale a uma análise da noção de problema), passa a analisar o que ele denomina “método individual”, ou seja, a atitude necessária, por parte da criança, para que a educação possa seguir seu curso. Essa atitude é analisada segundo três aspectos, sendo o primeiro aquilo que Dewey denomina retidão. Eis o que ele diz:

É mais fácil descrever o que se entende por retidão em termos negativos do que em termos positivos. A consciência de si, o constrangimento e o acanhamento são os inimigos que a

13. Ao lermos alguns estudos de sociologia, em especial os de B. Lahire, este não é, aparentemente, o caso. Vide, notadamente Tableaux de famille (1993), em que são retratados pais que, embora bastante "desprovidos culturalmente", criam seus filhos e filhas como príncipes e princesas, sem que isso em nada se pareça com aquilo que denominamos crianças rainhas. Vide, especialmente, o retrato intitulado: Salima, l'écriveuse disciplinée [Salima, a escrevedora disciplinada].

14. Para acompanhar essa tradição, haveria que mencionar Emerson e seu ensaio sobre La confiance en soi (2000) [A confiança em si mesmo]. Depois Nietzsche, que conhecia Emerson, e nele se inspira em alguns aforismos de Gai Savoir (1982) [O alegre saber]. Mas, além desses autores que partilham com Montaigne a ideia de um certo perfeccionismo, também em Kant (1993) podemos seguir este fio. Embora ele insista bastante, como se sabe, na disciplina e no dever, mesmo sendo o príncipe, em suas Réflexions sur l'éducation [Reflexões sobre a educação], um contramodelo educativo explícito, Kant não cessa de insistir nos perigos de tornar tímida uma criança; e afirma também, mais de uma vez, que ela, evidentemente, possui o direito de pedir tudo, e esse direito deve ser tornado efetivo. Por fim, há que mencionar Alain, e permito-me aqui remeter à concepção que ele tinha do juízo, descrita em meu livro: Le peuple enfant et l'école: pourquoi pas Alain? (L'Harmattan, 2012). ameaçam. Indicam que o indivíduo não se interessa diretamente por um assunto. Algo se produziu que desvia seu interesse para questões secundárias. Um indivíduo consciente de si pensa em parte no seu problema e, em parte, no que os outros acham de suas realizações. A energia desviada significa perda de capacidade e confusão das ideias. Adotar uma atitude e estar consciente da própria atitude são duas coisas bem distintas. No primeiro caso, existe espontaneidade ingênua e simplicidade. É o sinal de uma relação de unidade de intenção entre a pessoa e o assunto que a ocupa. No segundo caso, a atitude não é forçosamente repreensível ... Mas essa necessidade é ocasional e temporária .... "Confiança" expressa muito bem o que se entende por "retidão". Não deve, porém, ser confundida com a autoconfiança, que pode ser uma forma de consciência-de-si ou de "atrevimento". A confiança não se aplica ao que pensamos ou sentimos sobre nossa própria atitude: 
não é algo pensado. A confiança denota a retidão com que se vai ao encontro do que se tem a fazer. Denota não a confiança consciente na eficiência das próprias capacidades, e sim a fé inconsciente nas possibilidades da situação [grifo meu]. Significa alçar-se à altura das exigências da situação .... Quaisquer que sejam os métodos empregados pelo mestre, se desviarem a atenção do aluno daquilo que ele tem a fazer e a dirigirem para a sua própria atitude em relação ao que está fazendo, tais métodos alteram a retidão dos interesses e das ações. (Dewey, 2011, p. 259).

Temos aqui a mesma espontaneidade já analisada acima e a tese de que essa espontaneidade é a condição necessária para a educação em si. Montaigne falava em inclinação; Dewey (2011) fala em interesses e situação. 0 interesse, se expressa algo do eu, possui também uma vertente objetal: interessamo-nos por alguma coisa, pela situação, e nela buscamos as novas possibilidades que ela é passível de suscitar ${ }^{15}$.

É muito importante o fato de Dewey (2011) analisar esta “retidão” por contraste com uma atitude demasiado consciente; em breves palavras, talvez um tanto apressadas, Dewey (2011) analisa a consciência como presença do outro em mim, como atenção a esse outro que julga, como atenção à imagem que eu passo e que me preocupa.

Vai, inclusive, além, ao derivar, dessa (falsa) atenção a si mesmo, a autopersuasão quanto à eficácia das próprias capacidades. Segundo ele, ter confiança nas próprias capacidades é uma coisa; ter confiança nos recursos da situação e em sua exploração é outra, bem diferente. De um lado, a atenção centrada no eu e nos seus poderes; de outro, na sua relação, ou na relação com a exterioridade. 0 mundo é que nos propõe soluções, do mundo é que vêm as soluções que encontramos; ele, não nós, é que se revela cheio de recursos, mesmo sendo correto dizer que por meio de nossos deslocamentos e movimentos é que esses recursos se revelam. A educação principesca não é, portanto, a confiança em nossas capacidades, nem a imodéstia de achar que nós, e nós apenas, iremos triunfar de tudo; é, antes, a firme confiança na situação em si, em sua riqueza e em seus recursos, como decorrentes de nossos deslocamentos.

A “consciência” é, assim, a fonte ou a própria expressão da alienação, pelo menos uma consciência genérica que não sabe voltar breve e pontualmente àquilo que faz. E caberia, aqui, aprofundar a análise. 0 fato é que essa confiança, ou essa retidão referida por Dewey (2011), é, afi-

15. Sobre a noção de interesse, ver "L'école et l'enfant", capítulo 1. Sobre a crítica do objetivo da ação pensado como objetivo externo à atividade em si, "Démocratie et Education". 
nal, claramente definida: não tanto como confiança em si ou atrevimento, mas, antes, como "fé inconsciente nas possibilidades da situação".

Também aqui, como acima, não se trata, para os professores, de achar que seus alunos deveriam ser assim, ou de instituir essa atitude em obrigação, mas de ficar atentos ao fato de que também ela é fruto das relações em que os adultos colocam a criança. De modo que não é nada fácil obter esta "retidão", ou melhor - já que não é tão difícil assim -, o erro está em considerá-la como responsabilidade exclusiva da criança ou em achar que ela já é dada. Não é este o caso, e cabe a nós, como adultos, torná-la possível; ou, quando menos, não coibi-la.

Voltando à questão de nossa época e do nosso pós-modernismo. Se o pós-modernismo é, de fato, a valorização do indivíduo e da sua diferença, percebe-se que tal objetivo está longe de ser simples ou evidente. Está longe de ser essa facilidade em constituir supostas diferenças sobre as quais a educação deveria se calcar. $\mathrm{Na}$ forma da educação principesca, esse objetivo equivale a cultivar, e querer cultivar, a escolha ou as escolhas de si mesmo, a espontaneidade ou o alento exigidos para que o processo educativo possa seguir seu curso. Não é necessário, para tanto, um saber psicológico, no sentido de conhecer o que seria cada indivíduo. É necessário, contudo, um estudo das condições que, ou bem tornam impossível essa retidão e esse livre andar (é mais fácil), ou bem os tornam possíveis. O que será, afinal, que nos torna tímidos, medrosos, sem fé na situação ${ }^{16}$ ?

3. 0 indivíduo, as obras, a cultura: modalidades da subjetivação.

Por fim, e de forma demasiado breve, gostaria de abordar a segunda questão anunciada, que tange à relação entre o indivíduo e a cultura. E vou, mais uma vez, partir de Montaigne, pois, se há nele, como se viu, uma fortíssima preocupação em

16. Essas reflexões não são alheias ao último livro de $A$. Ehrenberg, La société du malaise. Ver resenha de Robert Castel em La vie des idées, assim como a resposta do autor. 17. Haveria aqui outra direção a ser seguida, concernindo não só ao "objeto didádico adequado" como ao “ modo de transmissão adequado". A ideia seria a seguinte: a própria pluralidade das vozes e dos modos de transmissão, sua diferença regrada, é o que é receptivo à diferença dos alunos. Permito-me, a esse propósito, remeter a meu artigo "Habitudes et/ ou discipline” ["Hábitos e/ou disciplina"], em Les disciplines de pensée, Artois Presses Université, 2013. criticar o conformismo e, por contraste, defender o indivíduo enquanto tal e sua espontaneidade, há também toda uma atenção às articulações dessa espontaneidade com as obras da cultura.

Procurei realçar, acima, um sentido de "proveitoso" que me parecia ir nessa direção. Queria agora estender esta resposta, articulando-a com uma reflexão sobre “o objeto didático adequado" ${ }^{17}$. 
3.1. A orientação propriamente didática do texto de Montaigne é ditada, em parte, pelo seguinte princípio: o que realmente pode educaré o comércio dos homens. Aescola é a escola do comércio dos homens. (“Comércio" deve aqui ser entendido não só como comércio dos bens, mas também das almas, das ideias, das palavras e dos costumes e, até mesmo, de nossas trocas com os animais, trocas entre nós, os vivos - em suma, qualquer que seja seu objeto). Uma das modalidades desse comércio são as viagens.

E eis o que diz particularmente Montaigne (1992, p. 119): “Que se lhe inculque no espírito uma honesta curiosidade em indagar sobre todas as coisas; ele irá reparar em tudo que de singular houver ao seu redor: uma construção, uma fonte, um homem, o local de uma antiga batalha, a passagem de César ou Carlos Magno”. ${ }^{18}$ Que ponto em comum entre esses diferentes exemplos nos permitiria apreender o conceito de “singular" (locais singulares) de que fala Montaigne? O sentido de singular, aqui, não parece ser o que se opõe a comum. Pelo contrário, os diferentes exemplos citados por Montaigne remetem ao singular como local de passagem. Assim, uma fonte é um lugar em que as pessoas vão e vêm, se encontram, se separam, trocam palavras. Da mesma forma, o lugar por onde passaram César e Carlos Magno, onde houve uma batalha, é um lugar que faz história: falamos sobre ele, e nele as pessoas também conversam e contam histórias. São lugares memoráveis, no sentido de serem lugares onde se depositaram nossas lembranças, lugares que deram o que falar e continuam a nos fazer falar; lugares de memória, no sentido de que nossa memória é feita por eles (e não o contrário, como se tivéssemos desde já uma memória em que fôssemos colocando o que bem nos aprouvesse): para além, e mesmo antes, de uma memória como faculdade, há aquilo que nos faz memória, que nos fará uma memória, aquilo de que nos lembramos e que nos constitui. Aquilo que “faz" memória, portanto. (Não existe separação abstrata entre uma faculdade e conteúdos indiferentes; o que existe são coisas que se guardam em nós e fazem nossa memória; lembranças como tais, aquilo que se guarda). 0 singular é, portanto: um lugar e um tempo de passagem e de lembranças; um lugar, alguém de que falamos e que faz memória, que fez memória pelo menos, e foi objeto de palavra.

\subsection{Gostaria de confirmar essa interpretação} da noção de "singular", apoiando-me no trecho que vem logo em seguida a este sobre as viagens, e que versa sobre os livros. Que livros se-
18. “Qu'on lui mette en fantaisie une honnête curiosité de s'enquérir de toutes choses; tout ce qu'il y aura de singulier autour de lui il le verra: un bâtiment, une fontaine, un homme, le lieu d'une bataille ancienne, le passage de César ou de Charlemagne." 
rão lidos? Não todos, mas, para começar, aqueles em que se verificou que muitos puderam encontrar, cada qual, diferentes bens. Assim, se há que ler e dar a ler Tito Lívio ou Plutarco, é pela seguinte razão: “Li em Tito Lívio cem coisas que tal pessoa não leu. Plutarco leu cem coisas além das que eu soube ler, e ao acaso, além das que o autor escreveu. Para uns, trata-se de um mero estudo de gramática; para outros, da anatomia da filosofia, em que se mesclam as partes mais abstrusas de nossa natureza." 19 (Montaigne, 1992, p. 120). E, mais claramente ainda: "É esta (os livros de Plutarco e o estudo dos costumes), entre todas, a meu ver, a matéria em que nosso espíritos se aplica das mais diferentes maneiras.” 20 (Montaigne, 1992, p. 120).

O critério apresentado por Montaigne é, portanto, o seguinte: os livros, as obras, os objetos de estudo que permitiram leituras diversas e apropriações singulares; livros, objetos, são recomendáveis pelo motivo de que muitos passaram por eles e neles encontraram seus bens próprios, e essa experiência, presume-se - e é claro que este segundo critério é tão necessário quanto o primeiro - pode ser repetida. É nesse sentido que eles têm valor, e não como objetos de estudo; o estudo não é senão o meio dessa apropriação ou desse uso singular, e não seu fim em si. 0 desafio está em poder repetir atos de apropriação e levar o indivíduo a constatar que ele pode tornar sua uma matéria estrangeira.

Podemos, então, isolar aqui o objeto didático adequado: é ele o objeto de passagem, aquele do qual se fala, que dá o que falar, em que muitos encontraram, e ainda encontram, seu bem singular. O singular é, portanto, o objeto, em que situamos a nós mesmos, ao mesmo tempo em que escutamos o que nele se diz. Situar a criança nas encruzilhadas, ou, como diria Michel Serres, nos trocadores, tanto para ela escolher um caminho quanto para ela ver a encruzilhada.

Isso não exclui o fato de alguns desses objetos, que "falavam para muitos", a nós não falarem mais ou já não estarem aptos a nos falar. Essa questão é, obviamente, objeto de discussão. 0 que tampouco exclui o fato de precisarmos lutar: alguns se

19. “J'ai lu en Tite-Live cent choses que tel n'y a pas lues. Plutarque y en a lu cent, outre ce que j'y ai su lire, et, à l'aventure, outre ce que l'auteur y a mis. A d'aucuns, c'est une pure étude grammairienne; à d'autres l'anatomie de la philosophie, en laquelle les plus abstruses parties de notre nature se pénètrent."

20. "C'est à mon gré, entre toutes, la matière à laquelle nos esprits s'appliquent de plus diverse mesure." apropriam desses locais singulares; se arvoram em seus defensores e protetores exclusivos e normativos; ou consideram sua própria apropriação, sua própria leitura, como a única correta, e que eles, somente eles, são seus legítimos herdeiros; sentem-se abandonados se já não podem pensar 
assim. Precisamos lutar também contra essas posições e construir internamente a possibilidade de esquivá-las.

Essas duas dificuldades não excluem, porém, a resposta genérica de Montaigne: o objeto didático adequado são esses lugares singulares.

\section{Conclusão}

A oposição entre indivíduo e cultura a mim parece, portanto, bastante abstrata. Não precisamos partir de um suposto individualismo contemporâneo para objetar-lhe uma atenção às obras e a uma cultura comum. Procurei ao menos mostrar que é absolutamente possível, do ponto de vista da educação, retomar e encampar este ideal do indivíduo.

Também procurei mostrar, contudo, que a preocupação com o indivíduo implicava, de forma bastante direta, em preocupação com a relação dele com a cultura e as obras humanas. Sua própria diferença se constrói como poder de repetição e variação.

A ideia é, portanto: quando procuramos acompanhar a relação entre indivíduo e cultura, somos forçados a modificar tanto nossa concepção do indivíduo como nossa concepção da cultura e de sua transmissão. No fundo, a diferença da cultura e das obras, quando essas de fato podem diferir, é o que permite e dá lugar à diferença individual. 


\section{Referências bibliográficas}

Boltansky, L., \& Chiapello, È. (1999). Le nouvel esprit du capitalisme. Paris: Gallimard.

Deleuze, G. (1968). Différence et répétition. Paris: PUF.

Dewey, J. (1970). L'école et l'enfant. Neuchâtel: Delachaux et Niestlé.

Dewey, J. (2011). Education et démocratie. Paris: Armand Colin.

Ehrenberg, A. (2010). La société du malaise. Paris: Odile Jacob.

Emerson, R. W. (2000). La confiance en soi (Essays, 1841-1844). Paris: Petite

Bibliothèque, Payot \& Rivages.

Johsua, S. (1999). L'école entre crise et refondation. Paris: La dispute.

Kambouchner, D. (1995). Notions de philosophie, tome 3 (Collection Folio Essais, n. 279). Paris: Gallimard.

Kant, E. (1993). Réflexions sur l'éducation. Paris: Vrin.

Lahire, B. (1993). Tableaux de famille (Hautes études). Paris: Gallimard; Éditions du Seuil.

Lyotard, J.-F. (1979). La condition postmoderne. Paris: Minuit.

Montaigne, M. (1992). Les Essais. Évreux: Arléa.

Nietzsche, F. Le gai savoir. Paris: Gallimard, 1982.

Vincent, H. (2012). Le peuple enfant et l'école: pourquoi pas Alain ? Paris: L'Harmattan.

Vincent, H. (2013). Habitudes et/ou discipline. In A. Firode, J.- F. Goubet, \& H. Vincent (Dir.), Les disciplines de pensée (pp. 107-126). Arras: Artois Presses Université.

Submetido à avaliação em 24 de julho de 2014, aprovado para publicação em 21 de outubro de 2014. 